\title{
Computation of a new mean dynamic topography for the Mediterranean Sea from model outputs, altimeter measurements and oceanographic in situ data
}

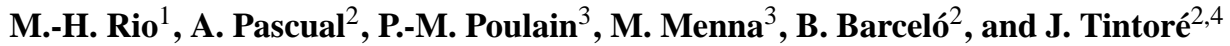 \\ ${ }^{1}$ CLS Space Oceanography Division, Ramonville-Ste Agne, France \\ ${ }^{2}$ IMEDEA(CSIC-UIB), Esporles, Spain \\ ${ }^{3}$ OGS, Trieste, Italy \\ ${ }^{4}$ SOCIB, Palma, Spain \\ Correspondence to: M.-H. Rio (mrio@cls.fr)
}

Received: 30 December 2013 - Published in Ocean Sci. Discuss.: 20 February 2014

Revised: 16 May 2014 - Accepted: 25 June 2014 - Published: 18 August 2014

\begin{abstract}
The accurate knowledge of the ocean's mean dynamic topography (MDT) is a crucial issue for a number of oceanographic applications and, in some areas of the Mediterranean Sea, important limitations have been found pointing to the need of an upgrade. We present a new MDT that was computed for the Mediterranean Sea. It profits from improvements made possible by the use of extended data sets and refined processing. The updated data set spans the 1993-2012 period and consists of drifter velocities, altimetry data, hydrological profiles and model data. The methodology is similar to the previous MDT by Rio et al. (2007). However, in Rio et al. (2007) no hydrological profiles had been taken into account. This required the development of dedicated processing. A number of sensitivity studies have been carried out to obtain the most accurate MDT as possible. The main results from these sensitivity studies are the following: moderate impact to the choice of correlation scales but almost negligible sensitivity to the choice of the first guess (model solution). A systematic external validation to independent data has been made to evaluate the performance of the new MDT. Compared to previous versions, SMDT-MED2014 (Synthetic Mean Dynamic Topography of the MEDiterranean sea) features shorter-scale structures, which results in an altimeter velocity variance closer to the observed velocity variance and, at the same time, gives better Taylor skills.
\end{abstract}

\section{Introduction}

The accurate knowledge of the ocean's mean dynamic topography (MDT) is a crucial issue for a number of oceanographic applications based on the use of altimeter sea level anomalies. The MDT may be calculated as the filtered difference between an altimeter mean sea surface (MSS Schaeffer et al., 2012; Andersen and Knudsen, 2009) and a geoid model. However, due to the lack of an accurate geoid, the computation of the MDT at short scales with sufficient accuracy is not trivial. The recent release of geoid models based on the use of GOCE data (Gravity field and Ocean Circulation Explorer; Pail et al., 2011) or a combination of GOCE and GRACE (Gravity Recovery and Climate Experiment) data (Bruinsma et al., 2013) has led to significant improvements for the calculation of the ocean MDT at scales down to $125 \mathrm{~km}$ (Mulet et al., 2012). However, in the Mediterranean Sea, where the Rossby radius is of the order of $10 \mathrm{~km}$, and the basin geometry characterized by narrow straits and numerous islands, this resolution is not sufficient to capture the small details and sharp coastal gradients of the circulation. A possible approach is to use so-called combined geoid models, where the missing short scales of the geoid are provided by altimeter measurements (by turning the altimeter MSS, which is the sum of the geoid and the MDT, into gravity anomalies that are then used in the calculation of the combined geoid). This has been done recently by Menna et al. (2013), showing potential improvement of the resulting MDT. However, this approach is based on the 


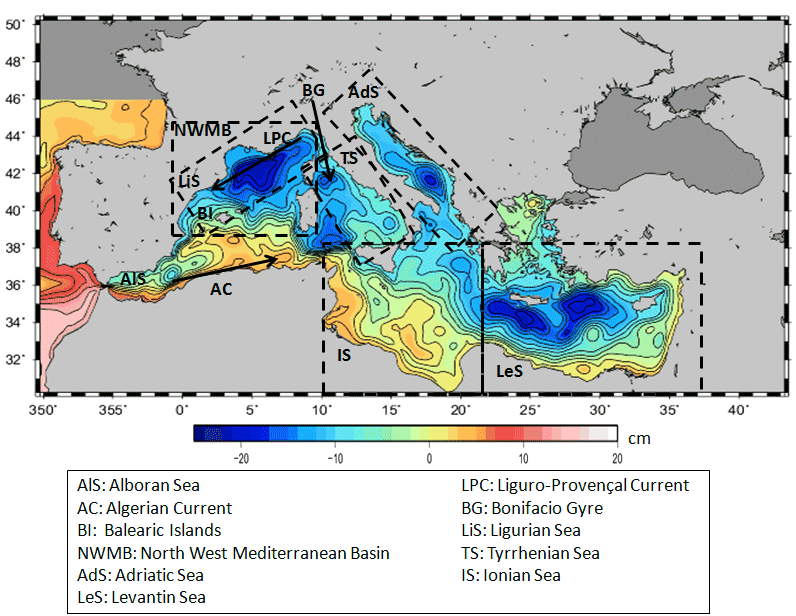

Figure 1. The Mean Dynamic Topography computed by Rio et al. (2007). The different sub-basins and currents mentioned in this paper are defined here.

use of an a priori MDT solution, and the independence of the final result to the choice of the a priori solution may therefore be questionable. Another approach is to combine different sources of information, including model outputs, in situ measurements and altimeter data. This was done for instance by Rio et al. (2007) and the resulting field is displayed in Fig. 1.

Recent studies (e.g., Bouffard et al., 2010) have identified limitations and inaccuracies of the MDT developed by Rio et al. (2007) pointing out the necessity of an update. In the frame of SOCIB (Balearic Islands Coastal Observing and Forecasting System) activities (Tintoré et al., 2013), an improved solution is presented in this paper, which has been made possible by the recent availability of updated time series of drifter data, simulations and new methodology enabling the inclusion of in situ profiles (Argo, CTD, etc.). The paper is organized as follows: first, we will describe in more details the methodology (Sect. 2) used and then present the different data sets that have been used for the calculation (Sect. 3). Then, in Sect. 4 we will describe the different processing steps that have been applied to the data to obtain synthetic observations of the MDT and the corresponding mean geostrophic velocities as described in the methodology section. The calculation of the MDT is based on a multivariate objective analysis and a number of sensitivity tests to different analysis parameters has been carried out, whose results are presented in Sect. 5. The final MDT of the Mediterranean Sea is described in Sect. 6 and validated in Sect. 7. Finally, we will end with a number of concluding remarks and perspectives.

\section{Method}

We have used the three-steps methodology described in Rio and Hernandez (2004) and Rio et al. (2005, 2007, 2011). The first step is to compute a large-scale estimate of the MDT (the so-called first guess). This can be achieved by averaging the outputs from an ocean model (Rio et al., 2007) or by filtering the difference between an altimeter MSS and a geoid model (Rio and Hernandez, 2004; Rio et al., 2005, 2011). Next, "synthetic" estimates of the MDT $(\langle h\rangle)$ and the associated mean geostrophic currents $\left(\left\langle u_{\mathrm{g}}\right\rangle,\left\langle v_{\mathrm{g}}\right\rangle\right)$ are calculated. These are simply obtained (Eq. 1), for a given time $t$ and geographical position $r$, by subtracting from the instantaneous in situ measurements of the ocean's dynamic topography $h(t, r)$ or the ocean geostrophic surface current $u_{\mathrm{g}}(t, r), v_{\mathrm{g}}(t, r)$, and the time variable $\left(h_{\mathrm{a}}^{\prime}(t, r), u_{\mathrm{a}}^{\prime}(t, r), v_{\mathrm{a}}^{\prime}(t, r)\right)$ component as measured by altimetry (i.e., the altimeter sea level anomaly (SLA) and the associated geostrophic velocity anomalies):

$$
\begin{aligned}
& <h>(r)=h(t, r)-h_{\mathrm{a}}^{\prime}(t, r), \\
& <u_{\mathrm{g}}>(r)=u_{\mathrm{g}}(t, r)-u_{\mathrm{a}}^{\prime}(t, r), \\
& <v_{\mathrm{g}}>(r)=v_{\mathrm{g}}^{\prime}(t, r)-v_{\mathrm{a}}^{\prime}(t, r) .
\end{aligned}
$$

The synthetic estimates are then used to improve the largescale solution (both for mean heights and mean geostrophic velocities) from the direct method through a multivariate objective analysis. In this formulation, used by Schlatter et al. (1976) or Schlatter (1975) for meteorological fields and first introduced in oceanography by Bretherton et al. (1976), the MDT $\langle h\rangle(r)$ is obtained at the spatial position $r$ as a linear combination (Eq. 2) of the observations $O\left(r_{i}\right)$. The observations are the synthetic estimates of the mean heights and the mean velocities obtained through Eq. (1).

$<>(r)=\sum_{i=1}^{N} \alpha_{i} O\left(r_{i}\right)$,

where $\alpha_{i}=\sum_{i=1}^{N} A_{i, j}^{-1} C_{r, j}$,

A is the observations covariance matrix and $\boldsymbol{C}$ is the covariance vector between the observations and the estimated field. Under a number of hypotheses (homogeneity and isotropy), the covariance between two locations $i$ and $j$ only depends on the distance $d_{i j}$ between the observations:

$$
\begin{aligned}
& \mathbf{A}=\left(<\sigma^{2}>C\left(d_{i j}\right)+<\varepsilon_{i} \varepsilon_{j}>\right)_{i, j=1, N} \text { and } \\
& \boldsymbol{C}_{r}=\left(<\sigma^{2}>C\left(d_{r j}\right)\right)_{j=1, N},
\end{aligned}
$$

where $\sigma^{2}$ is the a priori MDT variance, $C(r)$ is the a priori correlation function of the MDT field and $\varepsilon_{i}$ is the error on the observation located at $r_{i}$.

As in Rio and Hernandez (2004), we use the correlation function introduced by Arhan and de Verdiere (1985):

$C(r)=\left(1+r+\frac{1}{6} r^{2}-\frac{1}{6} r^{3}\right) e^{-r}$, 
where $r=\sqrt{\left(\frac{x}{x_{0}}\right)^{2}+\left(\frac{y}{y_{0}}\right)^{2}}$ and $x_{0}$ and $y_{0}$ are the zonal and meridian correlation radii of the MDT in the study area. The $C(r)$ function was defined for statistical characterization of the mesoscale variability in the North Atlantic. As we will see in Sect. 5.1 better models should be defined for the mapping of mean fields.

A linear relationship (i.e., geostrophy) links the mean dynamic height and the mean geostrophic velocities. As a consequence, the correlation function between the mean heights and the mean velocities can be deduced by the derivation of the MDT correlation function $C(r)$ (see Appendix A from Rio and Hernandez, 2004).

In theory, the mean of the estimated field needs to be zero (Bretherton et al., 1976). In practice, this hypothesis is fulfilled by first removing from the observations the large-scale a priori solution computed through the direct method. After inversion, the large-scale field is added back to the estimated field.

For each grid point where the interpolated field is computed, the weights on the surrounding observations therefore depend both on the distance to the grid point and on the observation error. The distance dependence is fully defined through the covariance field (variance and correlation radii) of the MDT. This method therefore requires the knowledge of both observation error and the a priori MDT covariance field. The a priori covariance information of Mediterranean Sea MDT will be determined using a modeled MDT.

\section{Data}

\subsection{Model outputs}

Outputs from two numerical models have been used to compute the first guess for the MDT computation. The first modeled MDT was computed averaging over the 1993-1999 period outputs from the $1 / 16^{\circ}$ MFS model (Mediterranean Forecasting System; Adani et al., 2011), while the second MDT uses outputs from a $1 / 12^{\circ}$ NEMO (Nucleus for European Modelling of the Ocean) model configuration (Beuvier et al., 2010) over the same 1993-1999 time period. They are displayed in Fig. 2a and b respectively.

\subsection{Hydrological profiles}

The hydrological profiles that have been used for this study were collected by IMEDEA(CSIC-UIB) (Mediterranean Institute for Advanced Studies) and SOCIB (Ruiz et al., 2009, 2012; Bouffard et al., 2010; Pascual et al., 2010; Heslop et al., 2012) and the CTD (conductivity-temperature-depth) profiles by IEO (Spanish Institute of Oceanography; IBAMar database, López Jurado et al., 2005; Alemany et al., 2010). This includes also Argo floats and CTD measurements from the EN3 database for the period ranging from 1993 to 2012. a-

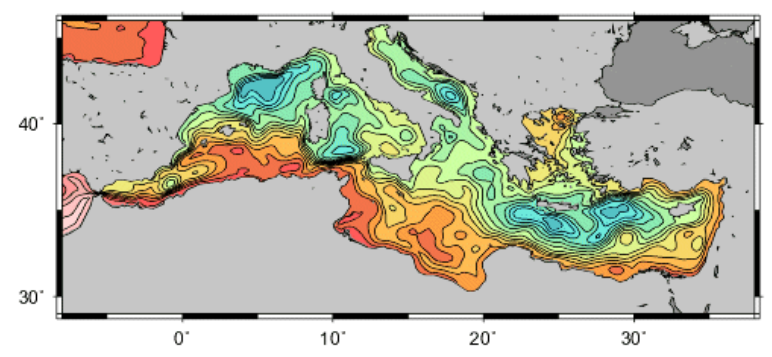

b-

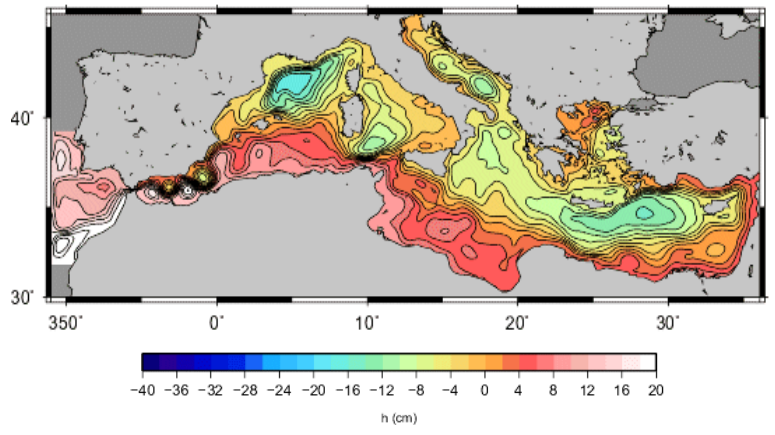

Figure 2. The mean dynamic topography of the Mediterranean Sea for the period 1993-1999 calculated averaging model outputs from (top) the MFS model and (bottom) the NEMO12 model.

The number of available profiles in $0.25^{\circ}$ by $0.25^{\circ}$ boxes is displayed in Fig. 3.

\subsection{Drifter velocities}

We used a data set of drifter velocities for the Mediterranean Sea available for the period 1993-2011. The drifting buoy velocities have been processed by Poulain et al. (2012) in order to extract from the drifter total velocities the geostrophic component (i.e., the component of the current resulting from the balance between the pressure gradient forces and the Coriolis force). To remove the ageostrophic components of the current, the drifter velocities have been first low-pass filtered $(36 \mathrm{~h})$ and sampled at $6 \mathrm{~h}$ intervals. Then the winddriven Ekman drifts have been removed using an ad hoc statistical regression using local wind products. We used all data until June 2011 for the MDT computation and kept the data from July to December 2011 for validation. The number of velocities available in $1 / 8^{\circ}$ boxes is displayed in Fig. 4.

\section{Computation of the synthetic data sets}

\subsection{Computation of the synthetic mean heights}

The hydrological profiles listed in Sect. 3.2 were used to compute dynamic heights relative to $350 \mathrm{~m}$ as displayed in Fig. 5. The reference depth choice results from making a compromise between the number of profiles available (the 


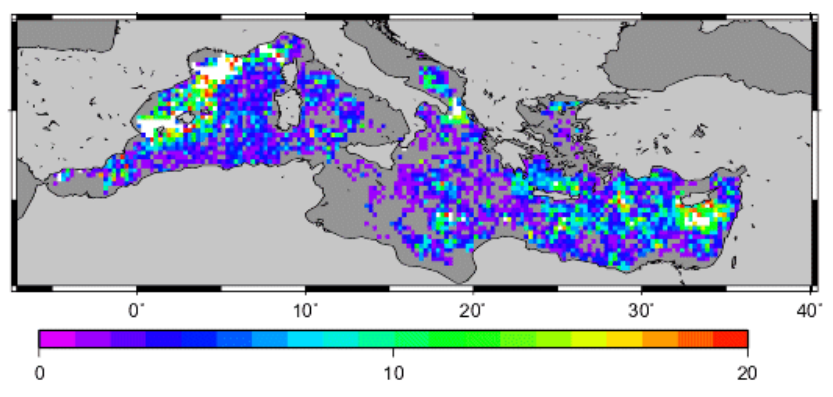

Figure 3. Number of hydrological profiles $(0-350 \mathrm{~m})$ in $0.25^{\circ}$ by $0.25^{\circ}$ boxes. Numbers in white boxes are greater than 50 . Boxes with no data are in grey.

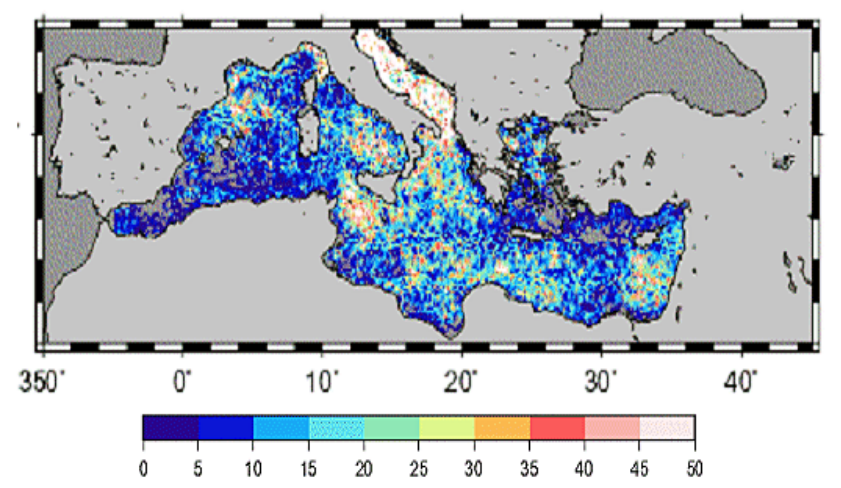

Figure 4. Number of drifter velocities in $1 / 8^{\circ}$ boxes. Numbers in white boxes are greater than 50 . Boxes with no data are in grey.

deeper the reference depth, the less the profiles available) and the dynamical content of the calculated dynamic heights (the deeper the reference depth, the more complete the captured baroclinic content). A deeper $(450 \mathrm{~m})$ reference depth was tested but led to a reduced number of profiles in the western part of the Ionian Basin, which is already poorly sampled using the $350 \mathrm{~m}$ reference depth (Fig. 5).

The use of these dynamic heights to compute synthetic mean heights of the Mediterranean Sea requires

1. extracting the temporal variability from the instantaneous dynamic height. The resulting quantity is therefore the mean dynamic height relative to the reference depth $(350 \mathrm{~m})$.

2. adding the missing mean component, i.e., the mean dynamic height at $350 \mathrm{~m}$ relative to the bottom and the barotropic contribution to the mean height (not measured by change in temperature and salinity).

To achieve point 1 , the idea is to interpolate at the position of the measured dynamic height the sea level anomaly (SLA, $h^{\prime}$ ) measured by altimetry and to extract from this SLA the steric contribution of the first $350 \mathrm{~m}, D h_{350}^{\prime}$, through the use of a parameter $\alpha_{350}$ such that

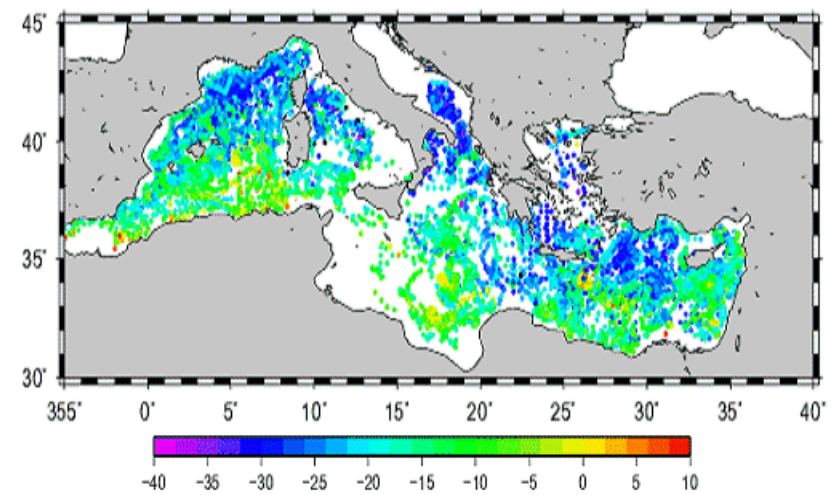

Figure 5. Dynamic heights computed relative to $350 \mathrm{~m}$ from the $T / S$ profiles available for this study. White stands for no data. The unit is centimeters.

$D h_{350}^{\prime}=\alpha_{350} \mathrm{SLA}$,

where $\alpha_{350}$ is determined through a least squares fit between the altimeter SLA and observations of $D h_{350}^{\prime}$ computed by subtracting a mean field from the instantaneous dynamic heights relative to $350 \mathrm{~m}$. This mean field was obtained by smoothing the observations using an objective analysis. Then $\alpha_{350}$ was obtained through a least squares fit over a 3-month moving window (Fig. 6). The coefficients range between 0.3 and 0.6 and, due to stratification, are maximal in summer and minimal in winter: for a stratified fluid in rotation, the ratio between horizontal and spatial scales is of the order of $N / f$, where $N$ is the Brunt-VäIsälä frequency and $f$ is the Coriolis parameter. During summer, when stratification is important, the vertical coupling is reduced and the baroclinic flow dominates, and the dynamic heights calculated from the temperature and salinity variations explain an important part of the full sea level anomaly measured by altimetry. The dashed lines in Fig. 6 represent the uncertainty envelope of the $\alpha_{350}$ parameter, calculated using the standard deviation of the regression error. The efficiency of using $\alpha_{350 \mathrm{~m}}$ times the altimeter SLA to remove the temporal variability of the dynamic heights is characterized in Fig. 7: the top panel shows the standard deviation of the dynamic heights calculated into $0.25^{\circ}$ by $0.25^{\circ}$ boxes. The middle and bottom panels show the standard deviation (expressed in percentage of the standard deviation of the dynamic heights) of the dynamic heights from which the temporal variability has been removed, either using the altimeter SLA (middle panel) or using only a part of it ( $\alpha_{350}$ SLA). Values greater than $100 \%$ thus correspond to boxes where subtracting the temporal variability from the signal leads to increased variability, i.e., some noise has been introduced. Using the full SLA to remove the variability increases the variability in most places, while removing only part of it through the use of the $\alpha_{350}$ coefficient leads to a reduction of the box standard 


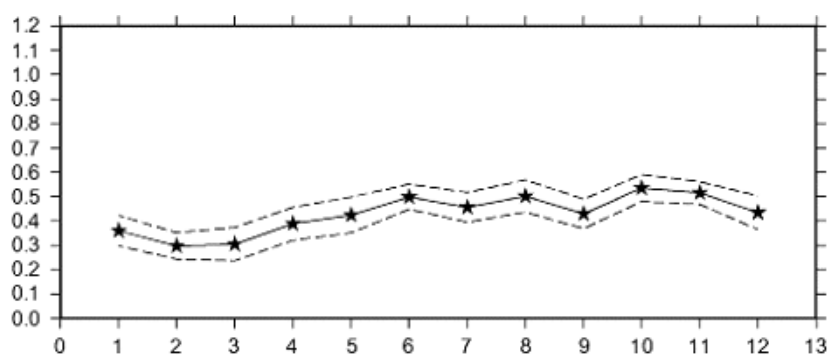

Figure 6. $\alpha$ parameter obtained using a 3-month moving window. The dashed lines give the uncertainty envelope of the obtained parameters.

deviation in most places, which makes us confident of the appropriateness of this approach. However, in some of the remaining boxes (percentage greater than $100 \%$, marked in white on the bottom panel of Fig. 7), noise is introduced by this method. We check (Fig. 8) that this corresponds to boxes with only few data and, again, that the approach is satisfying in most of the boxes. In these boxes, no correction of the variability is applied on the dynamic heights $\left(\alpha_{350 \mathrm{~m}}=0\right)$.

Once the temporal variability of the dynamic heights relative to $350 \mathrm{~m}$ has been removed using $\alpha_{350 \mathrm{~m}}$, we need to add the missing mean component, i.e., the mean dynamic height at $350 \mathrm{~m}$ relative to the bottom and the barotropic contribution to the mean height (not measured by change in temperature and salinity). This missing component is estimated as the difference between the MFS modeled MDT (Fig. 2a) and the mean synthetic dynamic heights relative to $350 \mathrm{~m}$ computed from observations. The MFS model is used here to be consistent with the first guess used for the MDT calculation (see Sect. 5.2). This approach is equivalent to considering that only the short spatial scales of the synthetic dynamic heights relative to $350 \mathrm{~m}\left(\mathrm{hdyn}_{/ 350}-\alpha_{350} \mathrm{SLA}\right)$ will be used in the inversion to correct the modeled first guess, i.e., it assumes that the modeled first guess is perfect (no associated error).

Due to the small number of profiles (Fig. 3), we decided to compute the mean synthetic heights in $0.25^{\circ}$ by $0.25^{\circ}$ boxes. The mean dynamic heights relative to $350 \mathrm{~m}$ and computed in $0.25^{\circ}$ by $0.25^{\circ}$ boxes are displayed in Fig. 6a. After adding the missing component, the mean synthetic heights that will be used for the MDT computation are displayed in Fig. $9 \mathrm{~b}$. An error estimate is also obtained for each $0.25^{\circ}$ by $0.25^{\circ}$ boxes; calculated as the box variance divided by the number of observations in the box. The obtained error is displayed in Fig. 9c. It is lower than $2-3 \mathrm{~cm}$ in most places. As stated before, this error does not take into account the error on the modeled first guess, and is therefore surely underestimated. a-

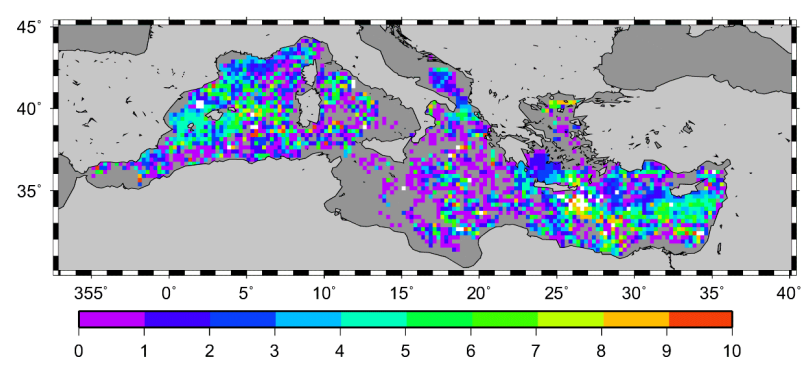

b-

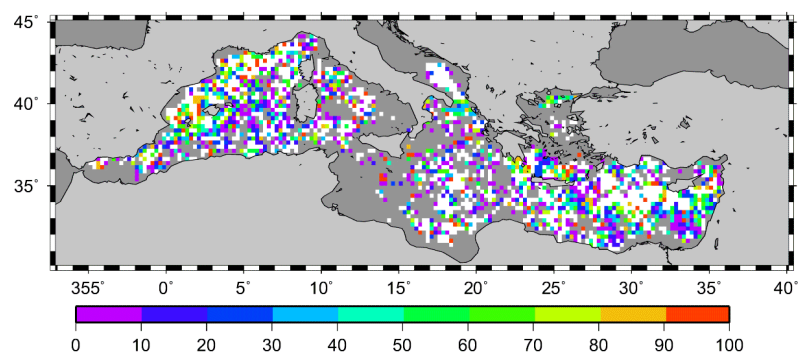

c-

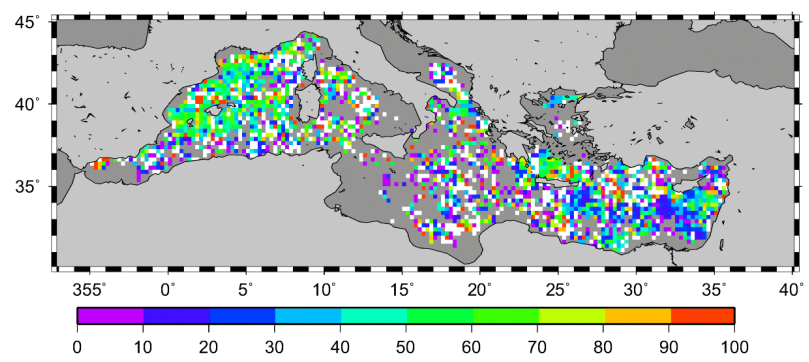

Figure 7. (a) Standard deviation of the dynamic heights $(\mathrm{cm})$. (b) Standard deviation of the dynamic heights corrected from the altimeter SLA, expressed in percentage of the dynamic heights' standard deviation. (c) Standard deviation of the dynamic heights corrected from the altimeter SLA times the $\alpha$ coefficient, expressed in percentage of the dynamic heights' standard deviation.

\subsection{Computation of the synthetic mean velocities}

We extracted from each geostrophic drifter velocity the temporal variability by subtracting the geostrophic velocity anomalies as measured by altimetry. We used the AVISO (Archiving, Validation, and Interpretation of Satellite Oceanographic Data) SLA maps computed specifically for the Mediterranean Sea area. The obtained "synthetic" mean geostrophic velocities computed in $1 / 8^{\circ}$ by $1 / 8^{\circ}$ boxes are displayed in Fig. 10. The size of the averaging box was chosen so as to keep a sufficient number of velocity measurements per box (Fig. 4), in order to have statistically significant estimates of the mean velocities and errors. 


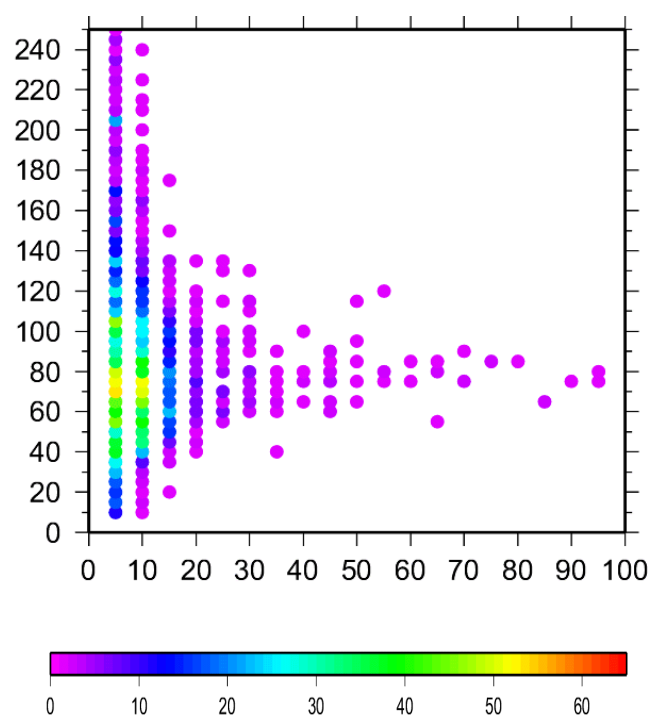

Figure 8. The signal's standard deviation reduction obtained as a function number of observations used to compute $\alpha_{350 \mathrm{~m}}$ (five observation intervals are considered). The color scale gives the number of boxes

In order to highlight the efficiency of the method for removing the temporal variability of the drifter velocities, we have computed the variance in $1 / 8^{\circ}$ by $1 / 8^{\circ}$ boxes of the geostrophic velocities (top panels in Fig. 11) and compared it to the variance obtained using the "synthetic" mean geostrophic velocities (bottom panels in Fig. 11). We checked that for both components of the velocity, the variance is reduced once the temporal variability has been removed. Quite interestingly this is valid even in coastal areas where the altimeter signal is expected to be less accurate (see the Ligurian or Algerian currents' variability, strongly reduced after removing the altimeter temporal variability). This result makes us confident that the final MDT product will be quite useful also close to the coast, mainly in strongcoastal-current areas.

Finally, an error is estimated in each $1 / 8^{\circ}$ by $1 / 8^{\circ}$ box, which takes into account the following.

- The individual velocity error estimates, computed as the sum of two contributions: the altimeter velocity anomaly errors (equal to $30 \%(40 \%)$ of the zonal (meridian) following Le Traon and Dibarboure, 1999, and Pascual et al., 2007) velocity on one side and the drifter geostrophic velocity error on the other side. This drifter geostrophic velocity error depends on the drifter type and is given in Table 2 of the paper by Poulain et al. (2012). It ranges between 2 and $5 \mathrm{~cm} \mathrm{~s}^{-1}$.

- The variance in the box where synthetic mean velocities are computed.

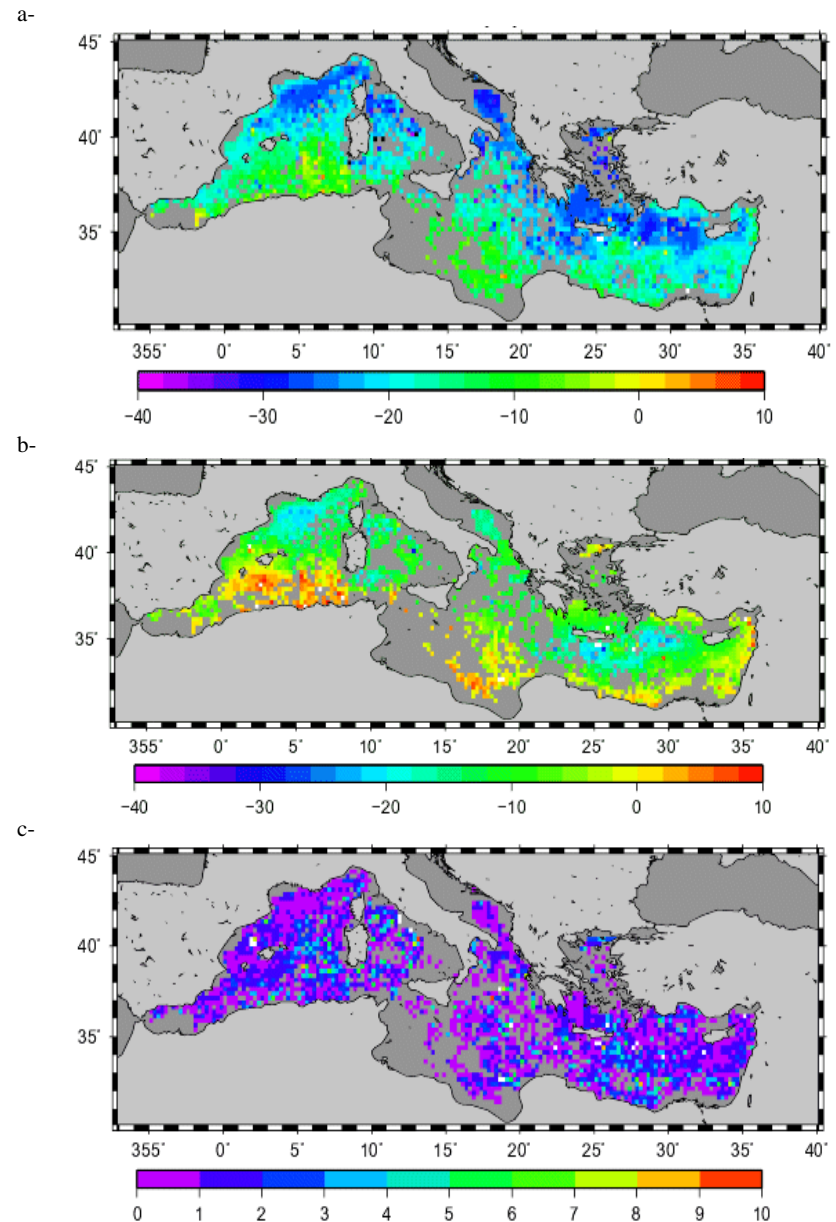

Figure 9. (a) The mean synthetic dynamic heights relative to $350 \mathrm{~m}$. (b) The synthetic mean dynamic topography estimates and (c) the corresponding errors. The unit is centimeters.

In each box, the error is taken as the maximum of the two contributions above, divided by the number of observations in the box. The resulting error field is shown in Fig. 12.

\section{Sensitivity tests}

In order to discriminate between the different MDTs obtained using different parameters (first guess, correlation scales, etc.) we have compared our different solutions to independent mean-synthetic velocities from drifter data. This independent data set is made of $24926 \mathrm{~h}$ velocity measurements spanning the period from July to December 2011 (this represents $1 \%$ of the total drifter data set). The measurements were processed as described in Sect. 4 in order to extract the mean geostrophic component of the current, but were not included in the SMDT-MED-2014 calculation. They sampled the Balearic Islands area, the northern tip of the Tyrrhenian Sea and the Ionian jet. 


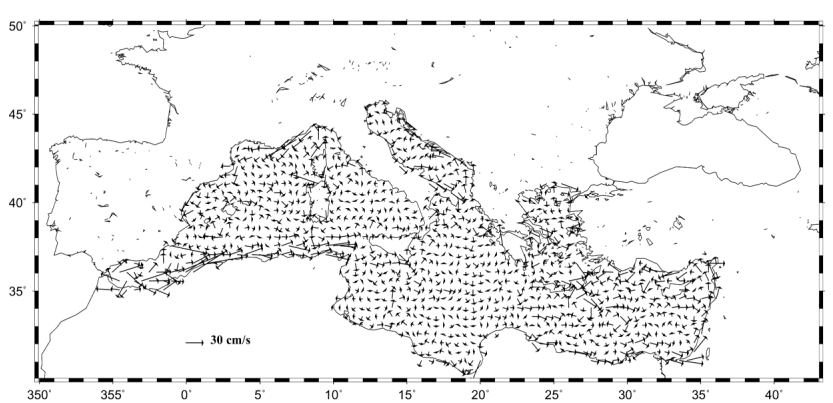

Figure 10. The synthetic mean velocities computed from drifter velocities and altimetry in $1 / 8^{\circ}$ boxes.

\subsection{Sensitivity tests to the objective analysis input parameters}

The a priori MDT covariance is a key parameter of the objective analysis that is used to map the MDT from the mean synthetic heights and velocities. To test the sensitivity of the final result to the input correlation scales, different correlation scales have been calculated, based either on modeled MDT (from the NEMO or the MFS system as described in Sect. 3.1) or obtained directly from the drifter mean geostrophic velocity information.

In effect, the correlation for the zonal (meridional) mean geostrophic velocities $U(V)$ is given by Eq. (3) (Eq. 4) below:

$$
\begin{aligned}
& <U, U>=\sigma_{U}^{2} \cdot \frac{\left(\frac{x}{x_{0}}\right)^{2} \cdot F(r)+\left(\frac{y}{y_{0}}\right)^{2} \cdot G(r)}{r^{2}}, \\
& <V, V>=\sigma_{V}^{2} \cdot \frac{\left(\frac{x}{x_{0}}\right)^{2} \cdot G(r)+\left(\frac{y}{y_{0}}\right)^{2} \cdot F(r)}{r^{2}},
\end{aligned}
$$

where $\quad F(r)=\left(1+r-\frac{1}{4} r^{2}\right) e^{-r}, \quad G(r)=$ $\left(1+r-\frac{7}{4} r^{2}+\frac{1}{4} r^{3}\right) e^{-r}$, and $r=\sqrt{\left(\frac{x}{x_{0}}\right)^{2}+\left(\frac{y}{y_{0}}\right)^{2}}$.

The correlation radii $x_{0}$ and $y_{0}$ were determined by least squares fit in $1^{\circ}$ by $1^{\circ}$ boxes.

The correlation scales obtained with the two ocean numerical models show similar patterns. In both cases, a strong anisotropy is observed, with zonal correlation scales (of the order of $150-200 \mathrm{~km}$ ) greater than the meridian correlation scales (of the order of $50-150 \mathrm{~km}$ ).

Different results were obtained using the analysis of the zonal drifter velocities (Eq. 3) or the meridional drifter velocities (Eq. 4). In particular, the zonal correlation scales are lower $(50-150 \mathrm{~km})$. Also, meridional correlation scales estimated from the meridional drifter velocities are much lower than those derived from the zonal drifter velocities (20$100 \mathrm{~km}$ instead of $60-120 \mathrm{~km}$ ). This discrepancy between the results obtained from $\langle U, U\rangle$ and $\langle V, V\rangle$ leads us to the

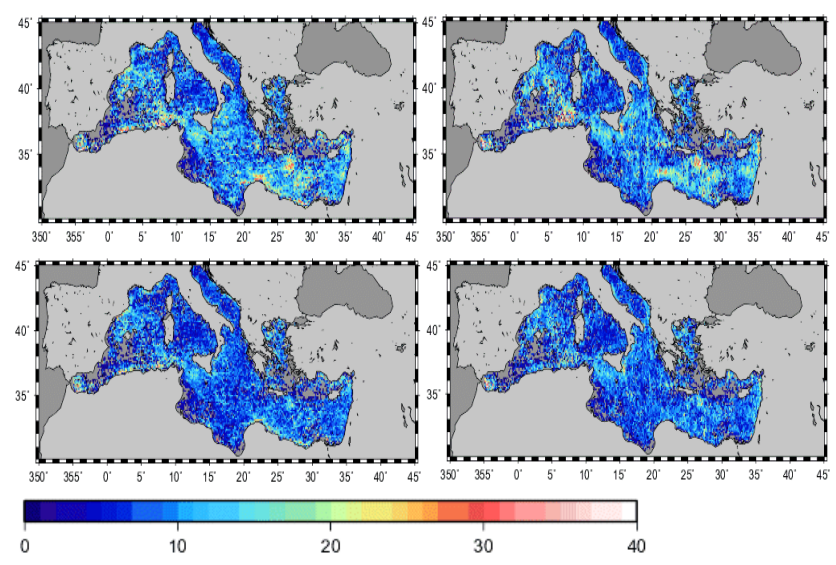

Figure 11. Standard deviation computed in $1 / 8^{\circ}$ boxes of (top) the geostrophic drifter velocities and (bottom) the synthetic mean velocities for the zonal (left) and meridian (right) component. The units are centimeters per second.

conclusion that the correlation functions $F(r)$ and $G(r)$ may not be appropriate for characterizing the mean circulation of the Mediterranean Sea. They are obtained assuming a correlation function $C(r)$ of the sea level that was defined by Arhan and de Verdiere (1985) for statistical characterization of the mesoscale variability in the North Atlantic. It is likely that better models can be defined for mapping of mean fields.

Four different MDT solutions were obtained using these different correlation scales, and a comparison to independent drifter velocities was done.

Better comparison to independent drifter velocities were obtained using the zonal analysis of drifter velocities as highlighted in Table 2, so that we used the correlation scales from Eq. (3) for the final MDT calculation. These scales are shown in Fig. 13.

The variance used was also computed from the drifter velocities' variance using Eqs. (3) or (4):

$\sigma_{h}^{2}=\sigma_{U}^{2} \cdot\left(\frac{f}{g}\right)^{2} \cdot \frac{3}{2} \cdot y_{0}^{2}=\sigma_{V}^{2} \cdot\left(\frac{f}{g}\right)^{2} \cdot \frac{3}{2} \cdot x_{0}^{2}$.

Slightly different results were obtained for $\sigma_{h}^{2}$ when starting from $\sigma_{U}^{2}$ or $\sigma_{V}^{2}$ in Eq. (5). We chose to take the maximum of the variance obtained. The final variance field is displayed in Fig. 11.

\subsection{Sensitivity tests to the first guess}

We have computed two different MDTs using as first guess the 1993-1999 mean from either the MFS or the NEMO model (Fig. 2). The top-left panel in Fig. 16 shows the height difference between these two first guesses. Important differences are visible, mainly in the Alboran Basin, the Ionian Basin and the Levantine Basin. Differences in amplitude can reach up to $20 \mathrm{~cm}$ but are lower than $8 \mathrm{~cm}$ in most places. For this sensitivity study, we have used only the synthetic 

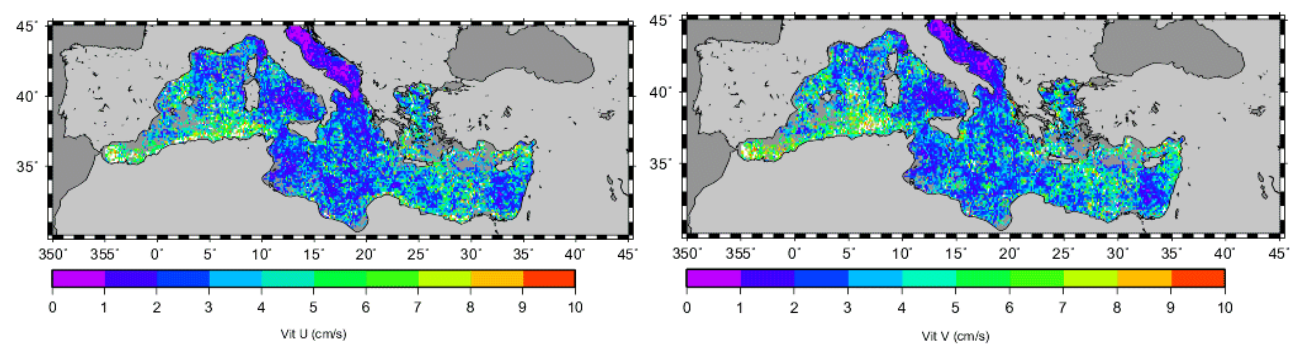

Figure 12. Error on the mean zonal (left) and meridional (right) velocities.

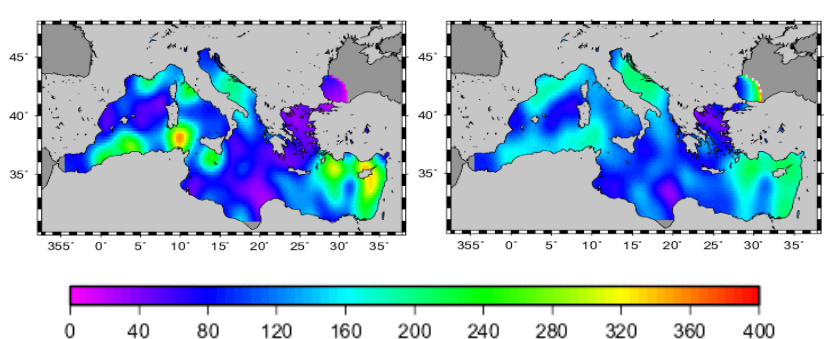

Figure 13. Zonal (left) and meridian (right) correlation scales $(\mathrm{km})$ computed from the drifters $(<U, U\rangle$ component) in $2^{\circ}$ boxes and filtered using a $200 \mathrm{~km}$ low-pass filter.

Table 1. Rms differences (in $\mathrm{cm} \mathrm{s}^{-1}$ ) between the processed independent drifter velocities and the altimeter velocities calculated using two different MDT solutions, starting either from the NEMO or the MFS model as first guess. The rms of the zonal (meridian) drifter velocities is $15.5(15.2) \mathrm{cm} \mathrm{s}^{-1}$.

\begin{tabular}{lrr}
\hline & $\begin{array}{r}\text { SMDT Vsynth } \\
\text { EbNEMO }\end{array}$ & $\begin{array}{r}\text { SMDT Vsynth } \\
\text { EbMFS }\end{array}$ \\
\hline$U_{\text {Drifter }}-U_{\text {Exp }}$ & 17.68 & 17.51 \\
$V_{\text {Drifter }}-V_{\text {Exp }}$ & 15.60 & 15.39 \\
\hline
\end{tabular}

mean velocities as input of the objective analysis. The topright panel in Fig. 16 shows the height differences between the two obtained MDTs. They are much lower than the differences between the two first guesses (see the Alboran Sea for instance), with amplitudes lower than $2-3 \mathrm{~cm}$. In addition, the height differences are rather large scale, meaning that the impact on mean geostrophic velocities is low. Indeed, it is lower than $1 \mathrm{~cm} \mathrm{~s}^{-1}$ in most places (bottom panels in Fig. 16).

Consequently, the statistical comparison to independent drifter velocities shows very little impact when one first guess is used instead of another (Table 1). Slightly lower root mean square (rms) differences are obtained using the MFS model compared to the NEMO model $\left(17.5 \mathrm{~cm} \mathrm{~s}^{-1}\right.$ instead of $17.7 \mathrm{~cm} \mathrm{~s}^{-1}$ for the zonal component, and $15.4 \mathrm{~cm} \mathrm{~s}^{-1}$ instead of $15.6 \mathrm{~cm} \mathrm{~s}^{-1}$ for the meridian component).

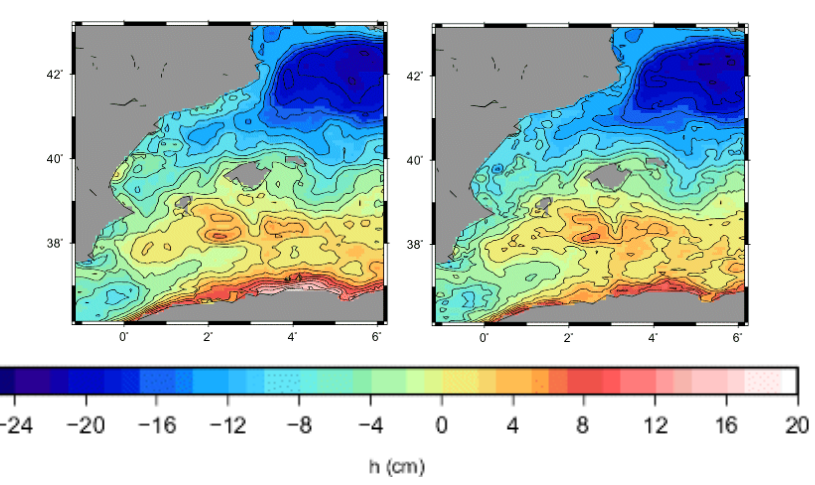

Figure 14. Mean dynamic topography computed in the Balearic Islands area using different correlation scales: (a) from the drifter's $<U, U>$ component, (b) from the drifter's $<V, V>$ component

In both cases, the altimeter zonal (meridian) velocity variance is overestimated (underestimated) compared to the drifter zonal (meridian) velocity variance.

Finally, we used the MFS model mean as first guess.

\section{The SMDT-MED-2014}

The synthetic mean heights and velocities were finally used to improve the MFS model mean through a multivariate objective analysis based on the parameters described in the previous section. The resulting SMDT-MED-2014 is displayed in Fig. 17. It was calculated on a $1 / 8^{\circ}$ resolution grid to benefit from the shortest scales of the mean synthetic velocities (computed in $1 / 8^{\circ}$ boxes). This is at a lower resolution compared to the resolution of the grid model from which the first guess was calculated $\left(1 / 16^{\circ}\right)$. However, the spatial scales of the average over the 1993-1999 period of the MFS model outputs may be much larger than the original model resolution grid (see top panel in Fig. 2).

A detailed view of the mean geostrophic currents calculated from the obtained MDT is given for six different areas of the Mediterranean Sea in Fig. 18 (Alboran Sea and Algerian Current; Balearic Islands; North West Mediterranean Basin; Tyrrhenian Sea and Adriatic Sea; Ionian Sea; Levantine Sea). 
Table 2. Rms differences (in $\mathrm{cm} \mathrm{s}^{-1}$ ) between the processed independent drifter velocities and the altimeter velocities calculated using four different MDT solutions, based on the use of correlation scales deduced from the analysis of the zonal or the meridional drifter velocities of the MFS MDT, or the NEMO MDT. The rms of the zonal (meridian) drifter velocities is $15.5(15.2) \mathrm{cm} \mathrm{s}^{-1}$.

\begin{tabular}{lrrrr}
\hline & $\begin{array}{r}\text { SMDT } \\
\text { RcDrifter } U, U\end{array}$ & $\begin{array}{r}\text { SMDT } \\
\text { RcDrifter } V, V\end{array}$ & $\begin{array}{r}\text { SMDT } \\
\text { RcMFS }\end{array}$ & $\begin{array}{r}\text { SMDT } \\
\text { RcNEMO }\end{array}$ \\
\hline $\mathrm{rms}\left(U_{\text {Drifter }}-U_{\operatorname{Exp}}\right)$ & 16.7 & 17.0 & 17.8 & 17.1 \\
$\mathrm{rms}\left(V_{\text {Drifter }}-V_{\operatorname{Exp}}\right)$ & 15.3 & 15.4 & 15.6 & 15.3 \\
\hline
\end{tabular}

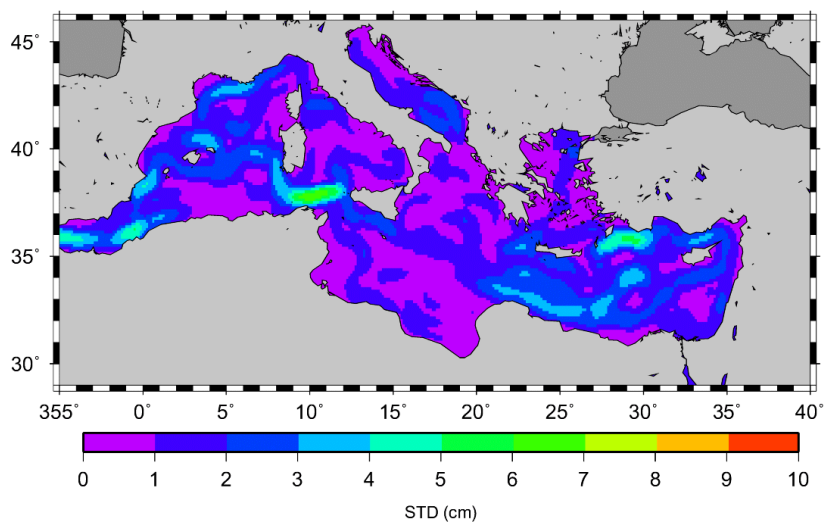

Figure 15. A priori standard deviation of the Mediterranean MDT computed in $1^{\circ}$ boxes from the MFS first guess. The unit is centimeters.

For comparison, for each area, we have also displayed the mean velocities as measured by drifters (first column), the previous SMDT05 solution from Rio et al. (2007) (second column), and the MDT from the MFS model, used here as first guess (third column).

Depending on the area, the mean currents are either reinforced (Liguro-Provençal current, coastal Adriatic currents, Algerian currents) compared to the initial first guess, or weakened (coastal current along the southeastern Spanish coast). The Alboran gyres are nicely resolved, while they were not captured by the MFS model. The previous SMDT07 solution featured a strong unrealistic current along the Spanish Catalan coast, which has almost disappeared in the new SMDT-MED-2014, in agreement with the MFS model and the drifter mean velocities. The Ligurian Current is also strongly modified in the new solution compared to the SMDT07, and the same holds for the Bonifacio gyre in the Tyrrhenian Sea, in good agreement with the drifter velocities.

\section{Validation using independent in situ measurements}

\subsection{Comparison to independent drifter velocities}

To validate the obtained SMDT-MED-2014 and quantify the improvements made compared to the previous solution, we
Table 3. Rms differences (in $\mathrm{cm} \mathrm{s}^{-1}$ ) of altimeter velocities obtained using the old and the new MDT solutions to independent geostrophic velocities. The rms of the zonal (meridian) drifter velocities is $15.5(15.2) \mathrm{cm} \mathrm{s}^{-1}$.

\begin{tabular}{lrr}
\hline & SMDT07 & SMDT-MED-2014 \\
\hline$U_{\text {Drifter }}-U_{\operatorname{Exp}}$ & 15.95 & 15.0 \\
$V_{\text {Drifter }}-V_{\operatorname{Exp}}$ & 14.94 & 14.1 \\
\hline
\end{tabular}

have used the same independent synthetic mean velocity data set as for the sensitivity studies.

Results are given in Table 3. The use of the new SMDTMED-2014 shows clear improvements compared to the SMDT07 solution, with reduced rms differences to drifter velocities.

\subsection{Comparison to independent hydrological profiles}

We use a data set of 912 independent CTD profiles not included in the previous computations to perform a comparison with the SOCIB-CLS MDT. The profiles come from cruises carried out during the period 2001-2012 in the area of the Balearic Sea by IEO (IBAMar López Jurado et al., 2005; Alemany et al., 2010), IMEDEA and SOCIB (Bouffard et al., 2010; Pascual et al., 2010; Ruiz et al., 2012; Heslop et al., 2012). For all CTD profiles, the dynamic height was computed with a common reference level of $350 \mathrm{~m}$. This is compared to the absolute dynamic topography (ADT) obtained by adding the gridded SLA fields to the previous MDT computed by Rio et al. (2007) and the SMDT-MED-2014 and then interpolated onto the position and time of the dynamic height profiles. The new SMDT-MED-2014 presents a better agreement with hydrological profiles as it is shown in the Taylor diagram (Fig. 19). The correlation increases from 0.54 to 0.60 , the rms differences decrease from 5.34 to $4.47 \mathrm{~cm}$ and the standard deviation (SD) of the ADT gets also closer to the dynamic height SD $(4.27 \mathrm{~cm})$ with SMDT-MED-2014 $(5.41 \mathrm{~cm})$ than with the previous version $(6.34 \mathrm{~cm})$. The fact that the ADT SD is still larger than the in situ SD may give an indication of the missing baroclinic (below $350 \mathrm{~m}$ ) and barotropic components of the dynamic height computation. 

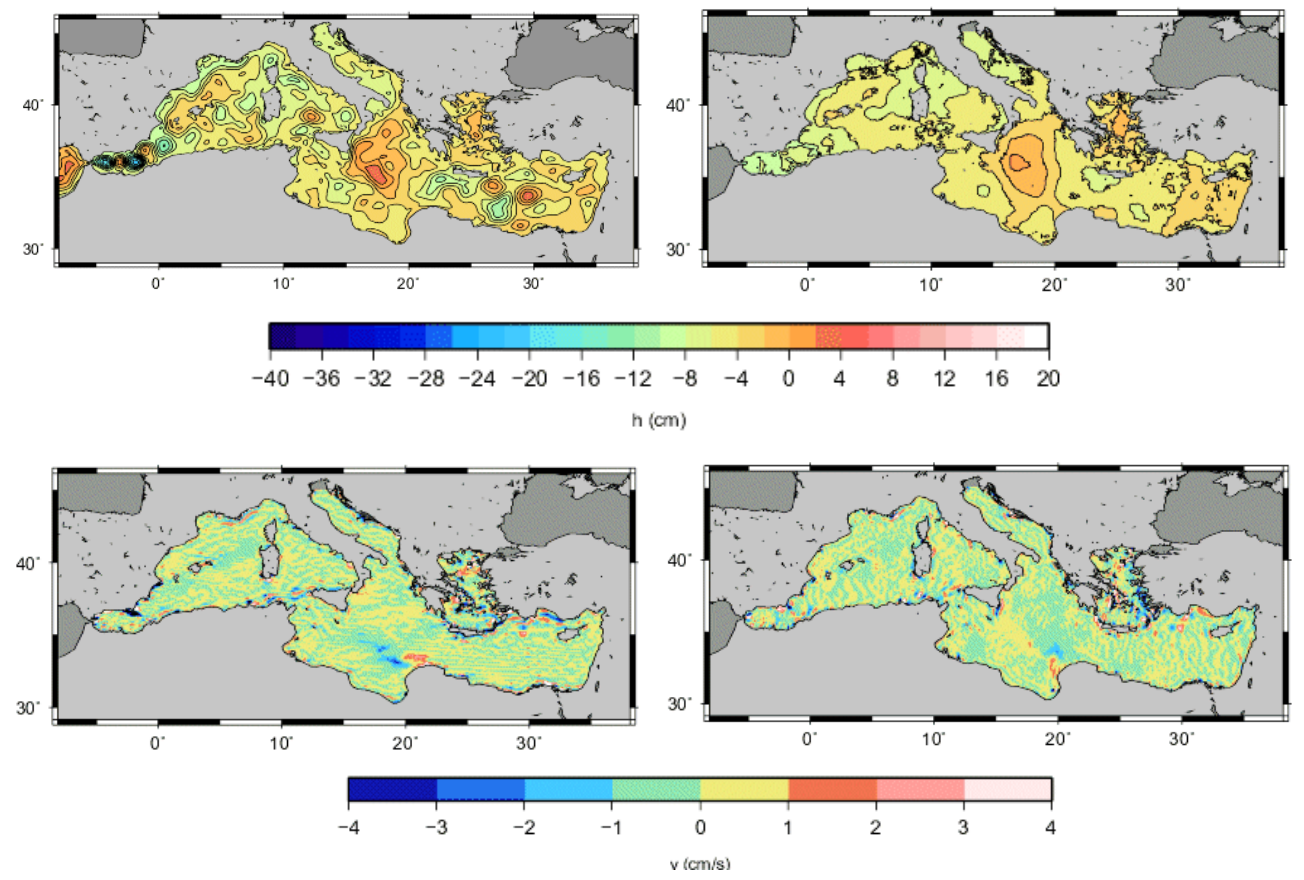

Figure 16. (Top left) Height difference between the MFS- and the NEMO-modeled MDT. Height (top right), zonal velocity (bottom left) and meridional velocity (bottom right) differences between the Mediterranean mean dynamic topography obtained from the inversion of the mean geostrophic velocities using the MFS or the NEMO first guess.

\subsection{Comparison to sea surface temperature}

A qualitative validation of the improvements achieved with the new SMDT-MED-2014 can be also analyzed through the comparison with sea surface temperature (SST) maps. Here we present one example in the Ligurian Basin (Fig. 20). They correspond to the mean SST fields averaged over one particular year (2007) and the equivalent mean circulation as derived from the addition of SLA and MDT using the previous MDT computed by Rio et al. (2007) and the SMDT-MED2014. For the SST we use the reanalysis produced by Marullo et al. (2007), which consists of a daily SST series obtained through an optimal interpolation of infrared AVHRR (Advanced Very High Resolution Radiometer) data with a $1 / 16^{\circ}$ resolution.

SST gradients give an indication of the mean surface cyclonic circulation of the Ligurian Sea, revealing the continuity along the coast of Corsica, the protrusion in the Gulf of Genova and the propagation along the French Mediterranean slope. The SST pattern also shows two cold cores, one centered at $6^{\circ} \mathrm{E}$ and the second at $7^{\circ} 30^{\prime} \mathrm{E}$. The SMDT07 solution also shows a general cyclonic circulation with higher values along the coast, although the protrusions close to Gulf of Genova are less pronounced than in the SST field and only one of the two cores is present (at around $6^{\circ} \mathrm{E}$ although the shape is quite different). Note also that there is a disruption of the circulation in the vicinity of Nice (at about $7^{\circ} \mathrm{E}$ ), with a gradient of ADT almost perpendicular to the

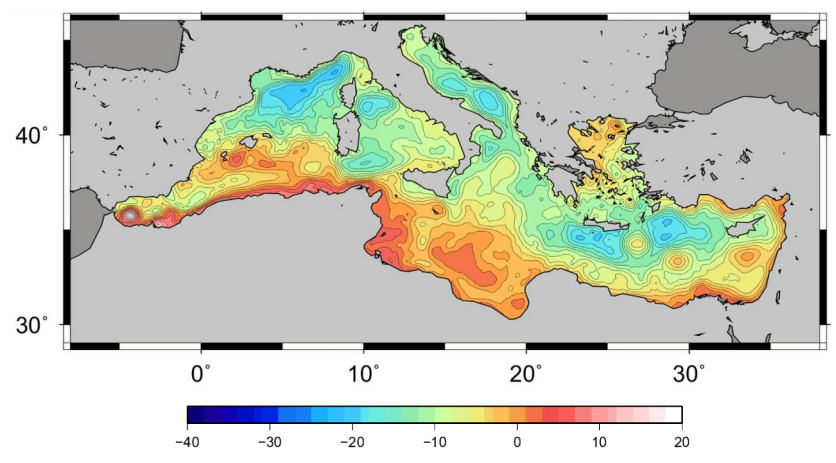

Figure 17. The SMDT-MED-2014. The unit is centimeters.

slope, indicating that the associated surface geostrophic currents are towards the coast and not parallel as it is expected from the SST patterns and also from previous studies (e.g., Pascual et al., 2013). On the contrary, the SMDT-MED-2014 solution shows a remarkable agreement with the SST fields. The cyclonic circulation is reinforced with a marked protrusion towards the Gulf of Genova, the two small cyclones are present with the same position and shape as SST data, and the artifact of associated currents towards the coast in the area of Nice has been corrected. 

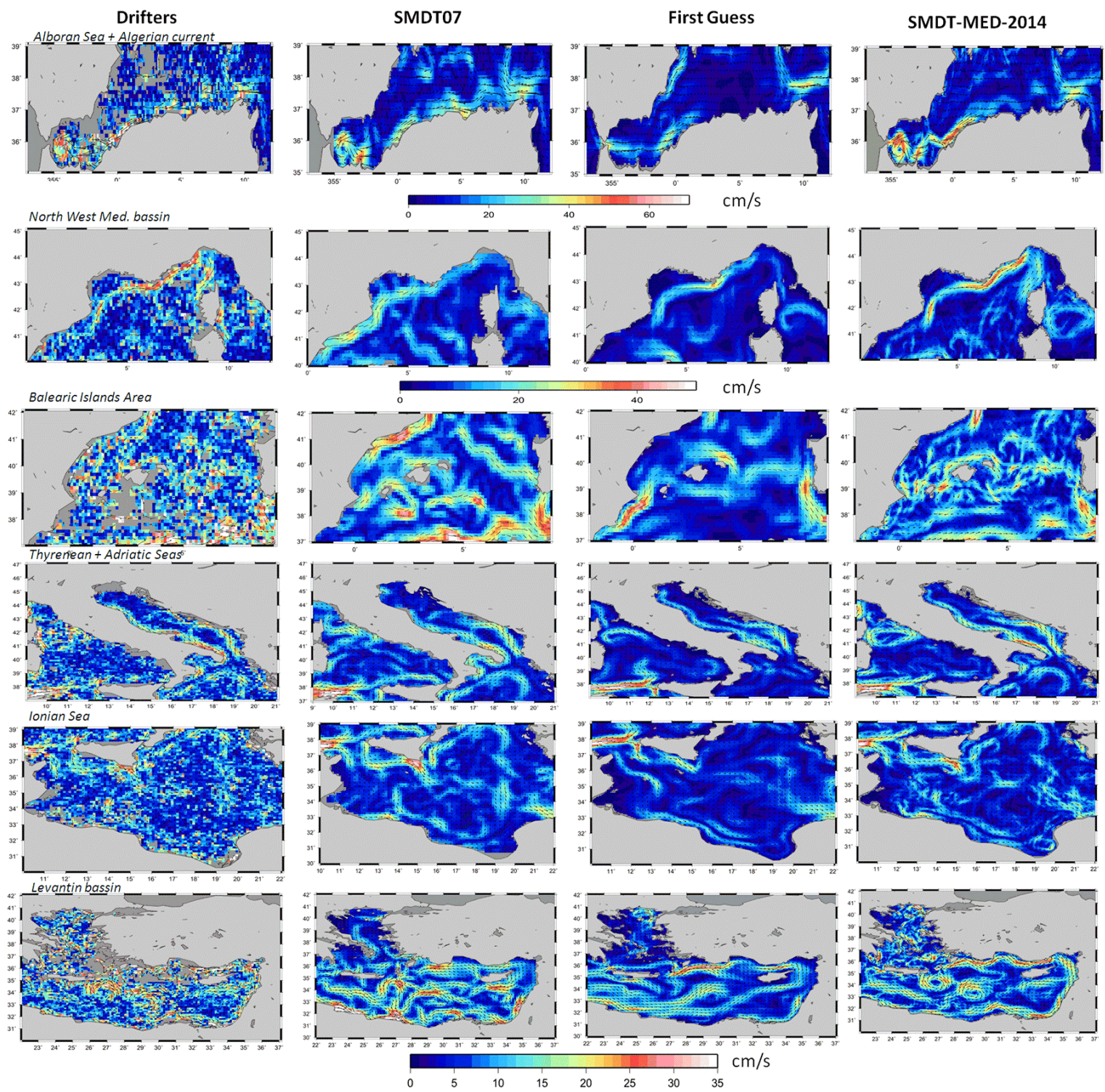

Figure 18. Mean circulation in different parts of the Mediterranean Sea as seen in the first column: the drifters; second column: the previous SMDT07 solution; third column: the MFS model first guess used for the computation of the SMDT-MED-2014; and fourth column: the SMDT-MED-2014.

\section{Potential impact of GOCE data}

In Rio et al. (2007), the use of a model's first guess was dictated by the insufficient accuracy of the geoid models for computing a large-scale MDT in the Mediterranean Sea from a filtered difference between a MSS and a geoid. Presently, significant improvements have been made in our knowledge of the geoid at scales down to approximately $150 \mathrm{~km}$ thanks to the longevity of the GRACE mission and the launch in march 2009 of the GOCE satellite, whose objective was to measure the Earth geoid at $100 \mathrm{~km}$ resolution with centimetric accuracy (Drinkwater et al., 2003). Still, the use of GOCE data to retrieve the mean dynamic topography in the
Mediterranean Sea is very challenging due to the geometry of the basin (many coastal areas, narrow straits, etc.) and the expected short scales of the ocean circulation (the Rossby radius number is of the order of $10 \mathrm{~km}$ ). The left panel in Fig. 21 shows the row differences between the CNES-CLS11 mean sea surface (Schaeffer et al., 2012) and the EGMDIR4 GOCE geoid model that was computed from 7 years of GRACE data and 2 years of reprocessed GOCE data (Bruinsma et al., 2013). The right panel in Fig. 21 shows the MDT obtained after filtering from the raw differences all scales shorter than $200 \mathrm{~km}$ using a simple isotropic gaussian filter. We see that the main gyres of the Mediterranean Sea circulation do not close (the cyclonic circulation in the North 


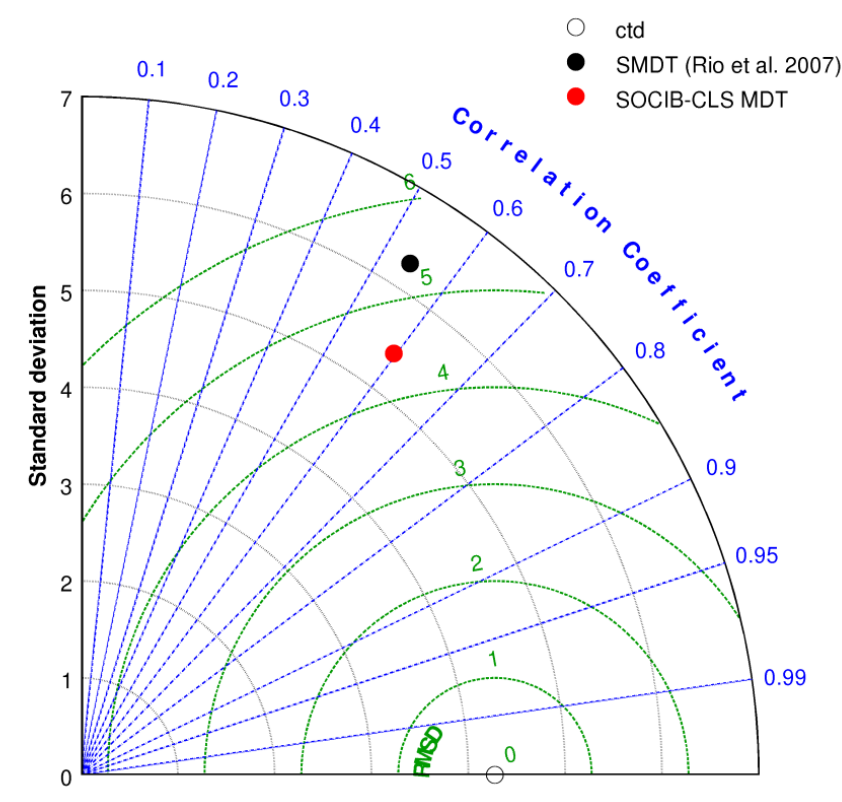

Figure 19. Taylor diagram displaying a statistical comparison with CTD of the SMDT07 solution and the SMDT-MED-2014 solution.

Western Mediterranean Basin, the gyres in the Adriatic Sea, the Alboran eddies, the anticyclonic circulation in the South Ionian Basin). The main issue when using a GOCE model in the Mediterranean Sea for the MDT computation is that the large geoid omission errors (satellite-only solutions are calculated for scales greater than around $80 \mathrm{~km}$, while the MSS resolves much shorter scales) coupled with a low oceanic signal variability result in a raw MSS-geoid signal characterized by a very low signal to noise ratio. The short-scale noise is too high to be correctly filtered. One approach may be the use of so-called combined geoid models: in these models (e.g., EIGEN-6C2; Foerste et al., 2012), GOCE data are used to estimate the geoid scales larger than approximately $100 \mathrm{~km}$ and the shorter scales are given by high-resolution gravity anomalies derived from altimeter MSS information. The objective is not to use this short-scale information for the MDT calculation but to reduce the amplitude of the signal to be filtered (the scales shorter than $100 \mathrm{~km}$ ) to increase the filter efficiency. Also, more sophisticated filters should be used, as for instance the optimal filter described in Rio et al. (2011). Finally, it is worth mentioning that a fifth release of the GOCE geoid models should be made available shortly by ESA (European Space Agency) to the scientific community. This release will benefit from an extended measurement period relative to the fourth release and, most notably, from a lower orbit configuration of the satellite during the last year of the mission, which should bring significant improvements at scales of $80-100 \mathrm{~km}$ and therefore enable a more accurate estimate of the ocean's mean dynamic topography in challenging areas such as the Mediterranean Sea.

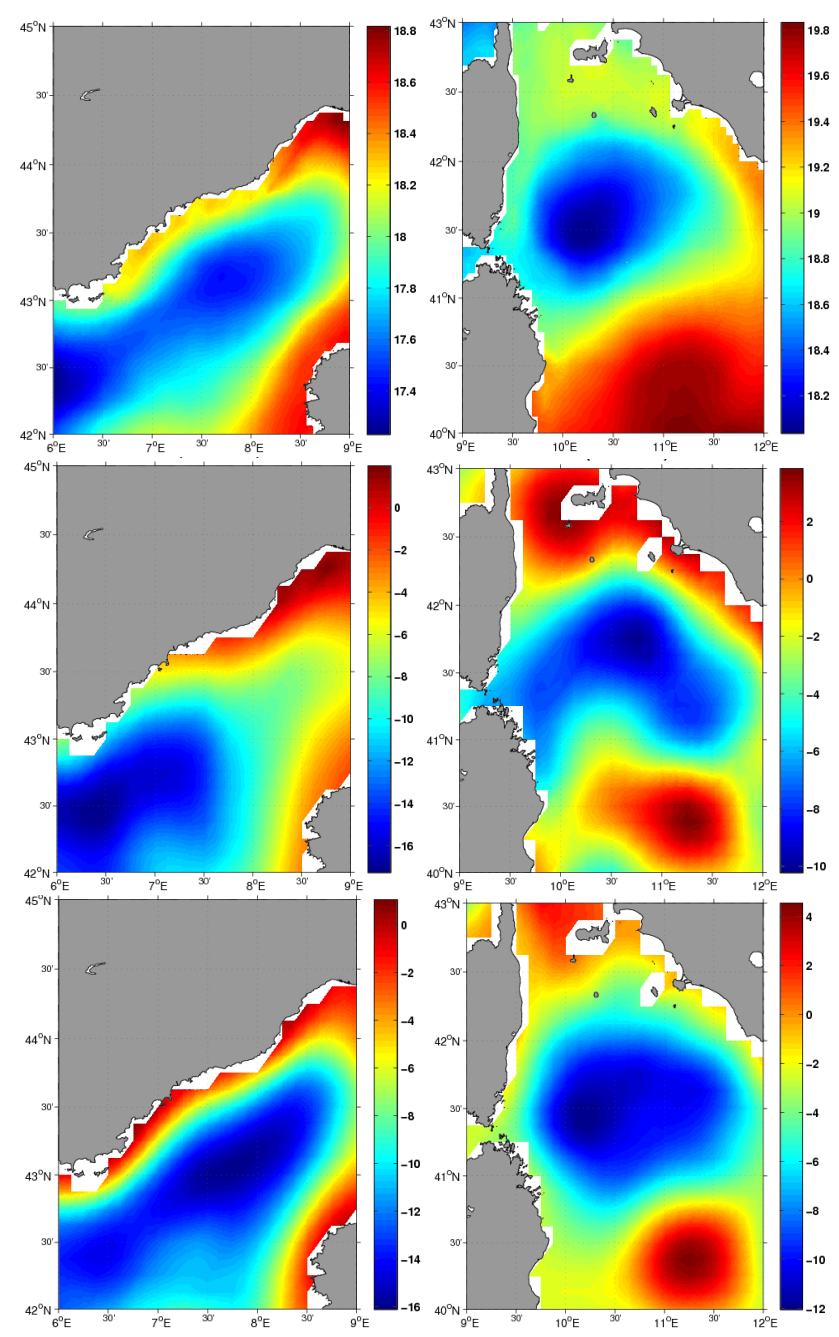

Figure 20. Top panels: mean SST patterns (in ${ }^{\circ} \mathrm{C}$ ) corresponding to the annual 2007 average for the Ligurian basin (left) and Tyrrhenian basin (right). Middle panels: mean circulation as derived from the previous SMDT solution. Bottom panels: mean circulation as derived from the SOCIB-CLS-MDT solution.

The use of GOCE data is one of the major perspectives of this work in the short term. We are confident that in the near future the use of an optimally filtered GOCE-based MDT could be used as first guess to invert the high-resolution synthetic mean heights and velocities and calculate a fully model-independent MDT solution of the Mediterranean Sea.

\section{Conclusions}

A new MDT was computed for the Mediterranean Sea that is available for calculating absolute dynamic heights and the corresponding geostrophic currents from altimeter sea level anomalies. It is based on the same methodology as the previous MDT computed by Rio et al. (2007). A number of improvements have been made possible by the use of extended 

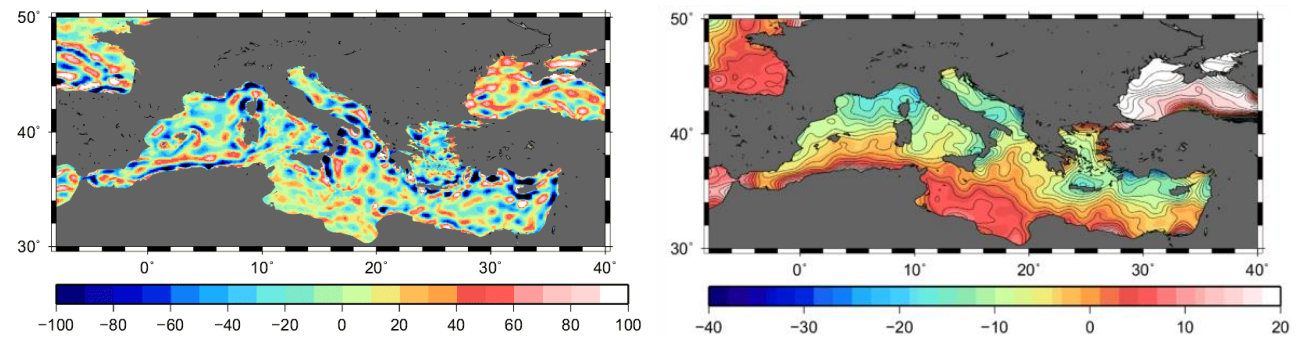

Figure 21. Left: raw difference between the CNES-CLS12 MSS and the EGM-DIR4 GOCE geoid. Right: A $200 \mathrm{~km}$ low-pass filter was applied on the raw differences.

data sets and refined processing. The new data set consisted of an updated data set of drifter velocities provided by OGS and a data set of hydrological profiles provided by IMEDEA. In Rio et al. (2007) no hydrological profiles were taken into account. This has required the development of dedicated processing. However, the impact of using these data, that are not very numerous, remains low at the moment.

A number of sensitivity studies have been carried out to obtain the most accurate MDT as possible. The main currents and main stationary structures of the Mediterranean Sea are found to be nicely resolved by this new MDT, with an improved description of important currents as the LiguroProvençal current, or known structures such as the Bonifacio gyre, compared to the previous SMDT07 solution. Also, spurious currents present in the SMDT07 solution have now disappeared (along the Spanish Catalan coast for instance). A systematic external validation to independent data (drifters, hydrological profiles, SST) has been made to evaluate the different parameter choices and validate the final SMDT-MED2014. However, only few independent data were available for validation so that the MDTs were tested mainly in the Balearic Islands area and the north Ionian jet.

For the future, further work about the definition of the correlation scales is needed, as well as an enhanced validation exercise, particularly in other parts of the basin. In addition, further work is needed to investigate the possibility of using the future release of GOCE geoid models (available in mid-2014) to compute a model-independent first guess in the Mediterranean Sea. Due to the high geoid error level compared to the rather low oceanic signal variance in the Mediterranean Sea, this will require the development of sophisticated filtering techniques.

Accurate knowledge of the MDT is known to strongly improve the performance of ocean modeling and forecasting system assimilating altimetry data (Haines et al., 2011). We therefore expect this new, improved MDT product to be highly useful in the context of the operational oceanography of the Mediterranean Sea.

Acknowledgements. The SMDT-MED-2014 was produced in the framework of a contract funded by SOCIB. We thank J. L. LópezJurado, R. Balbín and A. Aparicio from IEO as well as S. Ruiz and
E. Heslop from IMEDEA(CSIC-UIB) for providing CTD profiles that have been used either for the computation or validation of the SMDT-MED-2014. Mario Adani from INGV and Samuel Somot from Meteo-France together with Jonathan Beuvier from MercatorOcéan are acknowledged for providing the model's first guesses derived from MFS and NEMO simulations respectively.

Edited by: S. Sparnocchia

\section{References}

Adani, M., Dobricic, S., and Pinardi, N.: Quality Assessment of a 1985-2007 Mediterranean Sea Reanalysis, J. Atmos. Ocean. Tech., 28, 569-589, 2011.

Alemany, F., Quintanilla, L., Velez-Belchí, P., García, A., Cortés, D., Rodríguez, J. M., Fernández de Puelles, M. L., GonzálezPola, C., and López-Jurado, J. L.: Characterization of the spawning habitat of Atlantic bluefin tuna and related species in the Balearic Sea (western Mediterranean), Prog. Oceanogr., 86, 21$38,2010$.

Andersen, O. B. and Knudsen, P.: DNSC08 mean sea surface and mean dynamic topography models, J. Geophys. Res., 114, C11001, doi:10.1029/2008JC005179, 2009.

Arhan, M. and de Verdiere, C.: Dynamics of Eddy Motions in the Eastern North Atlantic, J. Phys. Oceanogr., 15, 153-170, 1985.

Beuvier, J., Sevault, F., Herrmann, M., Kontoyiannis, H., Ludwig, W., Rixen, M., Stanev, E., Béranger, K., and Somot, S.: Modeling the Mediterranean Sea interannual variability during 1961-2000: Focus on the Eastern Mediterranean Transient, J. Geophys. Res., 115, C08017, doi:10.1029/2009JC005950, 2010.

Bouffard, J., Pascual, A., Ruiz, S., Faugère, Y., and Tintoré, J.: Coastal and mesoscale dynamics characterization using altimetry and gliders: A case study in the Balearic Sea, J. Geophys. Res., 115, C10029, doi:10.1029/2009JC006087, 2010.

Bretherton, F. P., Davis, R. E., and Fandry, C. B.: A technique for objective analysis and design of oceanographic experiments applied to MODE-73, Deep Sea Res., 23, 559-582, 1976.

Bruinsma, S. L., Förste, C., Abrikosov, O., Marty, J.-C., Rio, M.-H., Mulet, S., and Bonvalot, S.: The new ESA satellite-only gravity field model via the direct approach, Geophys. Res. Lett., 40, 3607-3612, doi:10.1002/grl.50716, 2013.

Drinkwater, M. R., Floberghagen, R., Haagmans, R., Muzi, D., and Popescu, A.: GOCE: ESA's first Earth Explorer Core mission, in: Earth Gravity Field from Space - from Sensors to Earth Science, edited by: Beutler, G. B., Drinkwater, M. R., Rummel, 
R., von Steiger, R., Earth Gravity Field from Space - from sensors to earth sciences of Space Sciences Series of ISSI, Vol. 18, Kluwer Academic Publishers, Dordrecht, Netherlands, ISBN:14020-1408-2, 419-432, 2003.

Foerste, C., Bruinsma, S. L., Flechtner, F., Marty, J.-C., Lemoine, J.-M., Dahle, C., Abrikosov, O., Neumayer, H., Biancale, R., Barthelmes, F., and Balmino, G.: A new release of the EIGEN6C, Poster at AGU Fall Meeting 3-7 December, 2012, Website from the "International Geoid Service" (IGeS), available at: http://icgem.gfz-potsdam.de/ICGEM/modelstab.html (last access: 1 August 2014), 2012.

Haines, K., Johannessen, J. A., Knudsen, P., Lea, D., Rio, M.-H., Bertino, L., Davidson, F., and Hernandez, F.: An ocean modelling and assimilation guide to using GOCE geoid products, Ocean Sci., 7, 151-164, doi:10.5194/os-7-151-2011, 2011.

Heslop, E. E., Ruiz, S., Allen, J., López-Jurado, J. L., Renault, L., and Tintoré, J.: Autonomous underwater gliders monitoring variability at "choke points" in our ocean system: A case study in the Western Mediterranean Sea, Geophys. Res. Lett., 39, L20604, doi:10.1029/2012GL053717, 2012.

Le Traon, P.-Y. and Dibarboure, G.: Mesoscale mapping capabilities from multiple altimeter missions, J. Atmos. Ocean. Tech., 16, 1208-1223, 1999.

López-Jurado, J., Gonzalez-Pola, C., and Velez-Belchi, P.: Observation of an abrupt disruption of the long-term warming trend at the Balearic Sea, western Mediterranean Sea, in summer 2005, Geophys. Res. Lett., 32, L24606, doi:10.1029/2005GL024430, 2005.

Marullo, S., Buongiorno Nardelli, B., Guarracino, M., and Santoleri, R.: Observing the Mediterranean Sea from space: 21 years of Pathfinder-AVHRR sea surface temperatures (1985 to 2005): reanalysis and validation, Ocean Sci., 3, 299-310, doi:10.5194/os3-299-2007, 2007.

Menna, M., Poulain, P.-M., Mauri, E., Sampietro, D., Panzetta, F., Reguzzoni, M., and Sansò, F.: Mean surface geostrophic circulation of the Mediterranean Sea estimated from GOCE geoid models and altimetry data: initial validation and accuracy assessment, Bollettino di Geofisica Teorica ed Applicata, 2013.

Mulet, S., Rio, M. H., and Bruinsma, S.: Assessment of the preliminary GOCE geoid models accuracy for estimating the ocean mean dynamic topography, Mar. Geodesy, 35, 314-336, doi:10.1080/01490419.2012.718230, 2012.

Pail, R., Bruinsma, S., Migliaccio, F., Förste, C., Goiginger, H., Schuh, W.-D., Höck, E., Reguzzoni, M., Brockmann, J. M., Abrikosov, O., Veicherts, M., Fecher, T., Mayrhofer, R., Krasbutter, I., Sansò, F., and Tscherning, C. C.: First GOCE gravity field models derived by three different approaches, J. Geodesy, 85, 819-843, Springer, ISSN 0949-7714, doi:10.1007/s00190-0110467-x, 2011.

Pascual, A., Pujol, M.-I., Larnicol, G., Le Traon, P.-Y., and Rio, M.H.: Mesoscale Mapping Capabilities of Multisatellite Altimeter Missions: First Results with Real Data in the Mediterranean Sea, J. Marine Syst., 65, 190-211, 2007.

Pascual, A., Ruiz, S., and Tintoré, J.: Combining new and conventional sensors to study the Balearic Current, Sea Technol., 51, 32-36, 2010.

Pascual, A., Bouffard, J., Ruiz, S., Nardelli, B. B., Vidal-Vijande, E., Escudier, R., Sayol, J. M., and Orfila, A.: Recent improvements in mesoscale characterization of the western mediter- ranean sea: Synergy between satellite altimetry and other observational approaches, Sci. Mar., 77, 19-36, 2013.

Poulain, P.-M., Menna, M., and Mauri, E.: Surface geostrophic circulation of the Mediterranean Sea derived from drifter and satellite altimeter data, J. Phys. Oceanogr., 42, 973-990, doi:10.1175/JPO-D-11-0159.1, 2012.

Rio, M.-H. and Hernandez, F.: A mean dynamic topography computed over the world ocean from altimetry, in situ measurements, and a geoid model, J. Geophys. Res., 109, C12032, doi:10.1029/2003JC002226, 2004.

Rio, M.-H., Schaeffer, P., and Lemoine, J.-M.: The estimation of the ocean Mean Dynamic Topography through the combination of altimetric data, in-situ measurements and GRACE geoid: From global to regional studies, Proceedings of the GOCINA international workshop, Luxembourg, 2005.

Rio, M.-H., Poulain, P.-M., Pascal, A., Mauri, E., Larnicol, G., and Santoleri, R.: A Mean Dynamic Topography of the Mediterranean Sea computed from altimetric data, in-situ measurements and a general circulation model, J. Marine Syst., 65, 484-508, 2007.

Rio, M. H., Guinehut, S., and Larnicol, G.: New CNES-CLS09 global mean dynamic topography computed from the combination of GRACE data, altimetry, and in situ measurements, J. Geophys. Res., 116, C07018, doi:10.1029/2010JC006505, 2011.

Ruiz, S., Pascual, A., Garau, B., Pujol, I., and Tintoré, J.: Vertical motion in the upper ocean from glider and altimetry data, Geophys. Res. Lett., 36, L14607, doi:10.1029/2009GL038569, 2009.

Ruiz, S., Renault, L., Garau, B., and Tintoré, J.: Underwater glider observations and modeling of an abrupt mixing event in the upper ocean, Geophys. Res. Lett., 39, L01603, doi:10.1029/2011GL050078, 2012.

Schaeffer, P., Faugère, Y., Legeais, J. F., Ollivier, A., Guinle, T., and Picot, N.: The CNES_CLS11 Global Mean Sea SurfaceComputed from, 16 Years of Satellite Altimeter Data, Mar. Geodesy, 35, 3-19, 2012.

Schlatter, T. W.: Some Experiments with a Multivariate Statistical Objective Analysis Scheme, Mon. Weather Rev., 103, 246-257, doi:10.1175/1520-0493(1975)103<0246:SEWAMS>2.0.CO;2, 1975.

Schlatter, T. W., Branstator, G. W., and Thiel, L. G.: Testing a Global Multivariate Statistical Objective Analysis Scheme with Observed Data, Mon. Weather Rev., 104, 765-783, doi:10.1175/1520-0493(1976)104<0765:TAGMSO>2.0.CO;2, 1976.

Tintoré, J., Vizoso, G., Casas, B., Heslop E., Pascual, A., Orfila, A., Ruiz, S., Martínez-Ledesma, M, Torner, M., Cusí, S., Diedrich, A., Balaguer, P., Gómez-Pujol, L., Álvarez-Ellacuría, A., Gómara, S., Sebastian, K., Lora, S., Beltrán, J. P., Renault, L., Juzà, M., Álvarez, D., March, D., Garau, B., Castilla, C., Cañellas, T., Roque, D., Lizarán, I., Pitarch, S., Carrasco, M. A., Lana, A., Mason, E., Escudier, R., Conti, D., Sayol, J. M., Barceló, B., Alemany, F., Reglero, P., Massuti, E., Velez-Belchí, P., Ruiz, J., Gómez, M., Álvarez, A., Ansorena, L., and Manríquez, M.: SOCIB: the Balearic Islands Observing and Forecasting System responding to science, technology and society needs, Mar. Tech. Soc. J., 47, 101-117, doi:10.4031/MTSJ.47.1.10, 2013. 